\title{
DOMINÂNCIA DE TIPOS DE COMPROMETIMENTO EM DISTINTAS REDES
}

DOMINANCE OF TYPES OF COMMITMENT IN DIFFERENT NETWORKS

Recebido em 18.07.2017. Aprovado em 16.11.2017

Avaliado pelo sistema double blind review

DOI: http://dx.doi.org/10.12712/rpca.v11i5.1035

\section{Augusto Cezar D'Arruda}

Universidade Paulista (UNIP), São Paulo/SP

augusto.arruda@ifmt.edu.br

\section{Maria Carolina Arruda}

Universidade Paulista (UNIP), São Paulo/SP

caro190.arruda@gmail.com

\section{Lucimar Ferreira Almeida}

Universidade Paulista (UNIP), São Paulo/SP

lucimar.almeida@jna.ifmt.edu.br

\section{Ernesto Michelangelo Giglio}

Universidade Paulista (UNIP), São Paulo/SP

ernesto.giglio@gmail.com

\section{Resumo}

O trabalho propõe a correspondência entre tipos de comprometimentos em distintas redes, a partir do conceito relacional de comprometimento. Após revisão bibliográfica construiu-se um modelo com seis variações de comprometimento: (1) social; (2) racional; (3) econômico; (4) utilitarista; (5) afetivo e (6) institucional. Foram pesquisadas três redes da região de Cuiabá, uma de natureza comercial; uma com função social e uma de políticas públicas. Os resultados das análises das entrevistas indicaram sustentação da afirmativa de diferentes comprometimentos em redes distintas. Secundariamente, encontraram-se diferenças entre o tipo de comprometimento dominante em cada rede, o que possibilita o refinamento do desenho de pesquisa. $\mathrm{O}$ trabalho abre um campo de discussões teóricas sobre o comprometimento e as diferentes redes e também oferece um benefício metodológico na apresentação e teste de indicadores especialmente construídos para o fenômeno de redes.

Palavras-chave: Redes. Comprometimento. Mercado Solidário. Negócios. Políticas Públicas.

\begin{abstract}
The work proposes the correspondence between types of commitment in different networks, based on the relational concept of commitment. After a bibliographical review, a model was constructed with six commitment's variations: 1. Social, 2. Rational, 3. Economic, 4. Utilitarian, 5. Affective, 6. Institutional. The work selected three networks of Cuiabá region, one of commercial nature, one with a social objective and a one with public policies. The discourses' analysis confirm the proposition about different types of commitment in distinct networks. Secondly, differences was founded between the dominant commitment in each network. The work opens a field of theoretical discussions about the commitment and networks, and offers a methodological benefit in the presentation and test of indicators specially constructed for the phenomena of networks.
\end{abstract}

Keywords: Networks. Commitment. Solidarity Market. Business. Public Policy. 


\section{Introdução}

A busca de palavras mais citadas na produção acadêmica sobre redes mostra as expressões governança, inovação, estratégia, comprometimento. Sobre o comprometimento, as afirmativas seguem predominantemente abordagens sociais, isto é, definindo o comprometimento como disposição de um ator em valorizar os objetivos coletivos, colocando seus próprios interesses em segundo plano e não agindo de forma oportunista (ANDERSON, WEITZ, 1992). Também se encontram conceitos de comprometimento que utilizam princípios de racionalidade (MEYER, ALLEN, 1991), de ganhos financeiros, de visão utilitarista.

A questão que surge nessa variação de conceitos é: Será que para distintas redes, por exemplo, entre redes comerciais e redes de políticas públicas, alguns tipos de comprometimento seriam mais dominantes que outros? Por exemplo, será que numa rede com objetivo comercial, o tipo de comprometimento denominado utilitarista (cálculo dos ganhos advindos da relação de comprometimento) seria o dominante, ao passo que numa rede de ação social o comprometimento dominante seria o afetivo (satisfação pessoal em ajudar o outro)?

Analisando as variações dos conceitos encontrados e a origem dos trabalhos onde esses conceitos são apresentados, se teórico, ou se oriundos de pesquisas em campos específicos, criou-se a proposição: Existem diferentes tipos de comprometimento dominante para redes distintas.

Para responder a questão realizou-se o seguinte percurso metodológico: (a) busca de um conceito relacional convergente sobre comprometimento, a partir do fundamento da abordagem social de redes; (b) busca das variações conceituais de comprometimento; (c) definição operacional da distinção entre redes; (d) construção do desenho de pesquisa, com as correspondências esperadas; (e) construção e organização de indicadores de cada tipo de comprometimento e da distinção entre as redes; (f) construção de um roteiro estruturado de entrevista; (g) seleção das redes e dos atores; (h) coleta, organização e interpretação dos dados; (i) resposta ao problema de pesquisa.

Revisão bibliográfica buscando conceitos de comprometimento nos últimos dez anos, nos bancos de dados Proquest e Scielo encontrou diversificação de definições, das quais algumas foram selecionadas, como exemplos, e descritas no Quadro 1.

Quadro 1. Conceitos de comprometimento encontrados em revisão bibliográfica do período de 2006 a 2017.

\begin{tabular}{|l|l|}
\hline Autores & Expressões chave \\
\hline $\begin{array}{l}\text { Bozionelos (2008); } \\
\text { Kim (2010), Genari } \\
\text { (2013). Bastos (2014) }\end{array}$ & $\begin{array}{l}\text { Identificação do indivíduo com } \\
\text { normas, práticas e valores da } \\
\text { empresa }\end{array}$ \\
\hline Kim (2010) & $\begin{array}{l}\text { Comprometimento visando } \\
\text { obtenção de resultados }\end{array}$ \\
\hline Safari, Abdeali (2013) & $\begin{array}{l}\text { Comprometimento criando } \\
\text { identidade e cidadania }\end{array}$ \\
\hline Lee, Kim (2011) & Como envolvimento emocional \\
\hline Clarke (2006) & $\begin{array}{l}\text { Como estado psicológico de } \\
\text { prontidão para ajudar o outro }\end{array}$ \\
\hline $\begin{array}{l}\text { Braga (2008); Anjos } \\
\text { (2013) }\end{array}$ & $\begin{array}{l}\text { Vontade de permanecer no } \\
\text { grupo }\end{array}$ \\
\hline $\begin{array}{l}\text { Giglio, Ryngelblum } \\
\text { (2009) }\end{array}$ & $\begin{array}{l}\text { Responder ajudando o outro } \\
\text { que lhe depositou confiança e } \\
\text { solicitou ajuda }\end{array}$ \\
\hline
\end{tabular}

Fonte: Elaborado pelos autores, 2017.

Nesses trabalhos não se encontraram propostas de relação entre a natureza, ou distinção entre redes com um tipo específico de comprometimento, que é o objetivo do presente artigo. No entanto, o tema se revela importante, quando se consideram afirmativas dispersas nos artigos, mas convergentes, sobre a importância do comprometimento na organização da rede e na obtenção dos resultados. Se o comprometimento é componente importante na organização das redes, então conforme sua dominância culminaria em distintas organizações de redes?

Partindo dessa questão ainda sem resposta desenvolveu-se um suporte teórico para a proposição.

\section{Teoria de base}

Os conceitos de redes são diversos, com autores buscando reuni-los em grandes grupos (GRANDORI, 1997; OLIVER, EBERS, 1998), conforme dominância de afirmativas centrais e objetos de investigação. Além 
de paradigmas dominantes, a literatura sobre rede tambémé extensa em tipologias (MILES, SNOW,2007; ANTUNES, BALESTRIN, VERSCHOORE, 2010; HOFFMAN, MOLINA-MORALES, MARTÍNEZFERNÁNDEZ, 2007).

As teorias sobre redes também foram adotadas em campos diversos, além dos negócios, tais como em políticas públicas (BORZEL, 1998), redes de cooperação (VERSCHOORE, BALESTRIN, 2008) e redes de ações sociais (FRANÇA, 2004). O que difere o título da rede é o objetivo central a ser perseguido. Uma rede de políticas públicas se organiza para oferecer o serviço público, ao passo que uma rede de cooperação se organiza para facilitar as trocas de informações.

Um questionamento que surge dessas abordagens e tipologias é se existe variação da matriz de relacionamento entre os atores, conforme objetivos e estrutura da rede.

Conforme interpretação dos autores deste artigo, alguns paradigmas sobre redes que utilizam afirmativas de custos, de processos decisórios, de raciocínios de vantagens em estar nas redes e de estratégias podem ser agrupados numa classificação ampla que denominamos de abordagem racional/ econômica; em contraposição a um conjunto de afirmativas sobre relações sociais, jogos de poder, símbolos de comunicação, formação de clusters por afinidades culturais, valores e práticas, governança relacional e outras manifestações sociais, como ações solidárias; agrupados numa classificação ampla que denominamos de abordagens sociais de redes.

Mesmo existindo diversidade, na abordagem racional/econômica encontra-se o princípio que as empresas criam e entram em redes para resolver seus problemas de dependência de recursos e competitividade (WILLIAMSON, 1981; GULATI, GARGIULO, 1999; PFEFFER, SALANCIK, 1978). Os atores buscam suas parcerias conforme suas análises de vantagens e se comprometem nas ações de reciprocidade e desenvolvimento da rede. Estando integrado ao grupo, o sujeito espera obter algumas vantagens de processos e financeiras (MEYER, ALLEN, 1991).

A abordagem social afirma que as empresas criam e entram em redes a partir de uma matriz de relações sociais já existentes, ou que se formam no desenvolvimento da rede, sendo essa teia social que dirige os processos, decisões e comportamentos dos atores (GRANOVETTER, 1985; DIMAGGIO, POWELL, 1983). Os atores criam, desenvolvem e estabelecem laços relacionais, especialmente de confiança e comprometimento, que auxiliam na diminuição de resistências e conflitos para ações coletivas (XIAO, et al., 2010). Nessa abordagem o comprometimento se manifesta como resposta à solicitação de ajuda de atores do grupo e a disposição em auxiliar nos processos coletivos, mesmo sem um benefício individual imediato. Caracteriza basicamente um sistema social de trocas.

As duas grandes abordagens não são mutuamente exclusivas. É o pesquisador que escolhe seu caminho de interpretação, a partir de sua formação, ou pergunta de pesquisa, ou adequação do princípio ao fenômeno a ser investigado.

O tipo de rede a ser investigada também não é decorrência direta da opção teórica do pesquisador. Uma rede de políticas públicas pode ser investigada na perspectiva racional/econômica, ou na perspectiva social. A diferença está na valorização de categorias e variáveis de investigação. As redes apresentam aspectos comuns, independentemente das opções teóricas do pesquisador. Toda rede apresenta: (a) Natureza do objetivo predominante, que pode ser comercial, de política pública, um objetivo religioso, um movimento social, uma rede de cooperação tecnológica; (b) Origem e natureza dos problemas comuns que pode ser competição; intervenção do governo; proteção e ajuda ao cidadão; legalização; proteção de mercado; (c) Estrutura de ligações, de papéis e funções; (d) Objetivos comuns a serem perseguidos.

Além desses eixos comuns, os trabalhos sobre a extensa literatura de classificações de redes utilizam outras variáveis tais como formalidade ( $x$ informalidade), concentração geográfica (x dispersão), estrutura de ligações (aberta x fechada, laços fortes x fracos) (TICHY et al.; 1979; GRANDORI, 1997, GRANOVET'TER, 1985). Outras classificações se constroem a partir do objetivo básico das redes, classificando-as em redes de negócios, redes de políticas públicas, redes sociais e redes de cooperação, entre as principais.

Esses grupamentos, divisões, distinções levantam questões sobre a presença e atuação de categorias e variáveis que são constantemente colocadas como centrais nos trabalhos, tais como confiança, comprometimento, custos, relações de poder, 
resultados, formas de governança (BALESTRIN, VERSCHOORE, REYES, 2010). O presente artigo se ocupa especialmente das manifestações do comprometimento nas distintas redes.

O objetivo de uma rede de políticas públicas, por exemplo, é a criação de programas, oferecendo serviços e qualidade de vida em determinados segmentos sociais (SCHNEIDER, 2005). Para que o serviço se realize é necessária a participação direta dos próprios beneficiários dos serviços, que é o público. Será que os atores de redes de políticas públicas estão comprometidos com os esforços para os resultados?

As redes de economia solidária buscam apoiar empreendedores que não conseguem competir no mercado normal, de grande escala, criando associações e cooperativas. Seu principal objetivo é a inclusão social de pessoas em um sistema diferenciado de mercado (HIGA, 2005) e uma das características dessas redes é a participação de grandes empresas, com programas de responsabilidade social. Será que o comprometimento nesta rede se manifesta de forma distinta do que na rede de políticas públicas? Ações de responsabilidade social de empresas, como um curso de alfabetização para uma comunidade, poderia ser colocado na conta de comprometimento?

Uma rede de negócios tem como objetivo principal a competição no mercado, com soluções de custos e de aprendizagem que não se obtém de forma isolada e uma das suas características são as parcerias entre fornecedores, empresas e distribuidores, criando redes competitivas. Será que o comprometimento em assumir riscos e custos, por exemplo, pode ser afirmado como distinto do comprometimento em políticas públicas e do comprometimento em redes de economia solidária?

O trabalho persegue uma resposta para essa questão metódica da manifestação do comprometimento em distintas redes. Conforme se defende, a proposição é que para distintas redes correspondem diferentes tipos de comprometimento. Por exemplo, por hipótese, os atores das redes de negócios se relacionam com um comprometimento mais racional, isto é, o esforço coletivo visa um benefício comercial para si. Já os atores de uma rede de políticas públicas se relacionam com um comprometimento institucional, isto é, o esforço coletivo gera benefícios para o público visado e não diretamente para os atores.
A partir dessas diferenças das redes, quanto aos seus objetivos comuns, os problemas comuns e as formas de realizar as tarefas, foram selecionados os seguintes casos de estudo:

(A) Rede do Shopping Popular de Cuiabá, pois conforme pesquisas com dados secundários, incluindo contratos e acordos entre os atores, a rede tem como principal objetivo as negociações entre seus atores a fim de obter vantagens competitivas e melhorias na infraestrutura.

(B) Rede de políticas públicas da Secretaria de Meio Ambiente e Desenvolvimento Rural Sustentável do município de Várzea Grande, no Mato Grosso. A principal tarefa da rede é criar condições para que os pequenos agricultores realizem suas tarefas e negócios na perspectiva da sustentabilidade.

(C) Rede de economia solidária de um grupo de catadores de materiais recicláveis situado na cidade de Várzea Grande, no Mato Grosso. O objetivo principal da rede é a inclusão social dos catadores de rua e desempregados com dificuldades (como expresidiários). Uma grande empresa brasileira, com filial local, auxilia na infraestrutura e administração da cooperativa, principalmente ensinando os princípios do cooperativismo.

\section{Sobre Comprometimento}

A análise da revisão bibliográfica indicou convergência em seis conceitos de comprometimento, resumidos no Quadro 2. 
Quadro 2 . Conceitos de comprometimento.

\begin{tabular}{|l|l|}
\hline Tipos de Comprometimento & Conceito principal \\
\hline Comprometimento racional & As ações de comprometimento são planejadas para se obter algo em troca. \\
\hline Comprometimento Econômico & $\begin{array}{l}\text { Estar comprometido com fins de ganhos econômicos, ou seja, realizar as tarefas } \\
\text { que lhe são destinadas, como ator da rede, objetivando ganhos econômicos. }\end{array}$ \\
\hline Comprometimento utilitarista & $\begin{array}{l}\text { Esforço por ações de comprometimento para obter ferramentas, métodos, } \\
\text { técnicas que possam ser imediatamente utilizados no seu negócio e empresa. É } \\
\text { uma variação específica do comprometimento racional. }\end{array}$ \\
\hline Comprometimento institucional & $\begin{array}{l}\text { Estar forçado a agir em grupo por razões da regra, ou seja, existe uma dedicação } \\
\text { a mais por parte do ator uma vez que a regra para sua permanência assim o } \\
\text { força. }\end{array}$ \\
\hline Comprometimento Social & $\begin{array}{l}\text { Realizar algo a mais em favor do grupo e dos beneficiados, ou seja, é acreditar } \\
\text { nos atores e naquilo que a rede proporciona à sociedade e outros beneficiários } \\
\text { indiretos. }\end{array}$ \\
\hline Comprometimento Afetivo & $\begin{array}{l}\text { Envolver-se com o negócio por motivo de sentimento, convergência de valores, } \\
\text { ética e identidade. O sujeito tem a convicção de fazer algo útil ao participar do } \\
\text { grupo e desenvolve uma identidade de pertencer ao grupo. }\end{array}$ \\
\hline
\end{tabular}

Fonte: Desenvolvido pelos autores em 2017.

A partir desses conceitos, o artigo desenvolve e utiliza indicadores de comprometimento e investiga suas manifestações em distintas redes.

\section{Indicadores das manifestações do comprometimento}

Para a construção dos indicadores de cada tipo de comprometimento foram selecionadas definições dos trabalhos encontrados na busca bibliográfica ampla, isto é, sem restrição de período (MOWDAY, PORTER, STEERS, 1982; ROBERTS, O’REILLY, 1979; SALANCIK, 1977; MORGAN, HUNT, 1994; ANDERSON, WEITZ, 1992; MEYER, ALLEN, 1991) e também adaptações de teses brasileiras que investigaram o comprometimento (BERTOLI, 2015; GAMBA, 2014; BRAGA, MATTOS, SOUZA, 2008; REGO et al., 2007; SAFARI et al., 2013).

Quadro 3 . Indicadores de comprometimento.

\begin{tabular}{|c|c|c|}
\hline $\begin{array}{l}\text { Categoria do } \\
\text { comprometimento }\end{array}$ & $\begin{array}{l}\text { Convergência do } \\
\text { conceito }\end{array}$ & Indicador \\
\hline 1. Racional & $\begin{array}{l}\text { O ator realiza uma } \\
\text { operação mental } \\
\text { sobre ganhos e } \\
\text { custos em agir de } \\
\text { forma coletiva. }\end{array}$ & $\begin{array}{l}\text { 1.1. Aceitar as metas; } \\
\text { 1.2. Aceitar os valores e crenças; } \\
\text { 1.3. Participar das atividades coletivas; } \\
\text { 1.4. Ser pontual e assíduo nas reuniões e tarefas; } \\
\text { 1.5. Buscar desempenho e eficiência nas tarefas coletivas; } \\
\text { 1.6. Participar regularmente de decisões e reuniões; } \\
\text { 1.7. Esforço para permanecer no grupo e diminuir o risco de ter } \\
\text { que buscar alternativas de emprego; } \\
\text { 1.8. Esforço para permanecer no grupo porque sabe da existência } \\
\text { de poucas oportunidades em outros grupos, ou organizações. }\end{array}$ \\
\hline
\end{tabular}




\begin{tabular}{|c|c|c|}
\hline 2. Econômica & $\begin{array}{l}\text { Relação estritamente } \\
\text { financeira do ator } \\
\text { com a rede }\end{array}$ & $\begin{array}{l}\text { 2.1. Ficar no grupo por contabilizar a existência de poucas } \\
\text { alternativas de lucro se deixar esta rede; } \\
\text { 2.2. Não abandonar o grupo por contabilizar as perdas. }\end{array}$ \\
\hline 3. Utilitarista & $\begin{array}{l}\text { Uso dos recursos } \\
\text { obtidos na rede para } \\
\text { ações individuais. }\end{array}$ & $\begin{array}{l}\text { 3.1. Ficar no grupo para obter conhecimentos, processos e acesso } \\
\text { a mercados, facilitando a sobrevivência da empresa própria; } \\
\text { 3.2. Ficar a ajudar no grupo para não ter as dificuldades e } \\
\text { aborrecimentos de tentar entrar em outro; } \\
\text { 3.3. Se saísse do grupo teria que fazer grandes sacrifícios pessoais. }\end{array}$ \\
\hline 4. Institucional & $\begin{array}{l}\text { Ação em grupo por } \\
\text { razões de regra. }\end{array}$ & $\begin{array}{l}\text { 4.1. Há certa pressão legal que mantém o ator comprometido; } \\
\text { 4.2. Existem certas regras para que o ator continue no grupo, } \\
\text { mesmo existindo vantagens em sair; } \\
\text { 4.3. As pessoas já estão acostumadas com este grupo e criam } \\
\text { uma disposição de não ir embora, mesmo recebendo uma oferta } \\
\text { melhor; } \\
\text { 4.4. Existem obrigações legais e morais que fazem com que a } \\
\text { pessoa permaneça no grupo. }\end{array}$ \\
\hline 5. Social & $\begin{array}{l}\text { Relação social do } \\
\text { ator com a rede. }\end{array}$ & $\begin{array}{l}\text { 5.1. Intenção de continuar no grupo, mantendo os } \\
\text { relacionamentos; } \\
\text { 5.2. Ajudar o outro, mesmo que tenha um esforço pessoal, ou } \\
\text { sem benefício próprio imediato; } \\
\text { 5.3. Os componentes participam das reuniões e das decisões } \\
\text { para serem aceitos, pois têm medo do que irá ser resolvido nas } \\
\text { reuniões; } \\
\text { 5.4. Assumir responsabilidades de ações conjuntas, confiando que } \\
\text { o outro irá cumprir sua parte. }\end{array}$ \\
\hline 6. Afetiva & $\begin{array}{l}\text { Relação emocional } \\
\text { do ator com os } \\
\text { outros atores. }\end{array}$ & $\begin{array}{l}\text { 6.1. Orgulho em dizer a outras pessoas que faz parte desse grupo; } \\
\text { 6.2. Existência de uma forte relação de simpatia com esse grupo; } \\
\text { 6.3. Fazer parte do grupo como se fosse uma família; } \\
\text { 6.4. Percepção de que os atores cumprem os acordos; } \\
\text { 6.5. Desejo de continuar na rede; } \\
\text { 6.6. É uma realização pessoal fazer parte desse grupo. }\end{array}$ \\
\hline
\end{tabular}

Fonte: Desenvolvido pelos autores em 2017.

A partir dos textos sobre tipos de comprometimento; sobre manifestação do comprometimento em casos distintos de redes e sobre as características das redes; criou-se, como proposta, um desenho de correspondência entre cada tipo de comprometimento com cada tipo de rede a ser investigada, conforme apresentada na Figura 1. A linha cheia de cada correspondência indica a hipótese de dominância de comprometimento e a linha pontilhada indica a hipótese da segunda dominância. Apesar do caráter inferencial, o desenho não foi construído aleatoriamente, mas segue afirmativas sobre comprometimento e sua presença em casos de redes. 
Figura 1. Modelo de relação de comprometimento com redes de distintas naturezas.
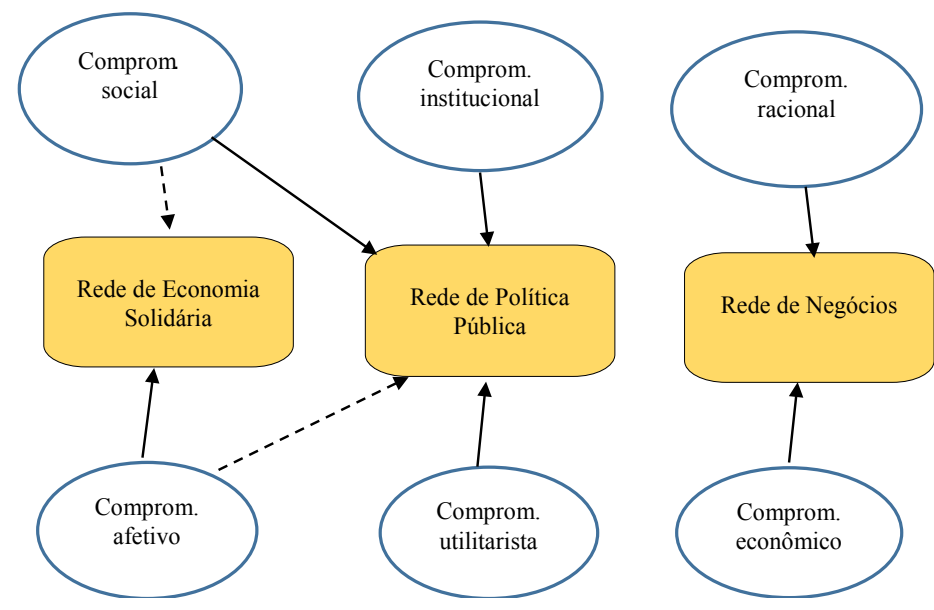

Fonte: Elaborado pelos autores em 2017.

\section{Metodologia}

O trabalho utiliza estratégia qualitativa, com dados coletados em entrevistas com roteiro estruturado, construído a partir dos indicadores. A segunda fonte de dados vem de fontes secundárias, especialmente atas de reuniões, notícias nos jornais locais, entrevistas técnicas com consultores que auxiliaram na formação das redes, documentos do governo, como Diário Oficial e duas visitas às empresas foco de análise, o Shopping Cuiabá e a Asscavag.

A seleção das redes deve-se aos critérios de estarem na mesma região sócio demográfica e apresentarem características distintas bem definidas.

O Quadro 4 apresenta um resumo das características distintivas das redes.

Quadro 4 . Características das Redes investigadas.

\begin{tabular}{|l|l|l|l|}
\hline & $\begin{array}{l}\text { Rede de Políticas Públicas ambientais } \\
\text { na qual se inclui a Secretaria do Meio } \\
\text { Ambiente e Desenvolvimento Rural } \\
\text { Sustentável }\end{array}$ & $\begin{array}{l}\text { Rede de Economia solidária } \\
\text { de material reciclável na qual } \\
\text { se inclui a Asscavag }\end{array}$ & $\begin{array}{l}\text { Rede de negócios na qual se } \\
\text { inclui o Shopping Popular de } \\
\text { Cuiabá }\end{array}$ \\
\hline $\begin{array}{l}\text { Problemas } \\
\text { comuns } \\
\text { aos atores }\end{array}$ & $\begin{array}{l}\text { a) Problemas locais de } \\
\text { desenvolvimento rural; } \\
\text { b) Atores do governo e da sociedade } \\
\text { se sensibilizam com os problemas do } \\
\text { meio ambiente; } \\
\text { c) Conscientização do meio ambiente } \\
\text { por parte da população da cidade. }\end{array}$ & $\begin{array}{l}\text { a) Falta de condições de } \\
\text { trabalho; } \\
\text { b) Falha na execução nas leis } \\
\text { ambientais; } \\
\text { c) Catadores solitários } \\
\text { são explorados pelos } \\
\text { comerciantes. }\end{array}$ & $\begin{array}{l}\text { a) Falta de leis, regulamentos } \\
\text { e normas que legitimem esses } \\
\text { trabalhadores; } \\
\text { b) As leis colocam os } \\
\text { ambulantes em situação } \\
\text { irregular; } \\
\text { c) Os ambulantes são } \\
\text { pressionados pelos lojistas. }\end{array}$ \\
\hline $\begin{array}{l}\text { Objetivos } \\
\text { comuns }\end{array}$ & $\begin{array}{l}\text { a) Implementar os planos de } \\
\text { desenvolvimento rural; } \\
\text { b) Criar mecanismos e realizar ações } \\
\text { de conscientização das pessoas } \\
\text { e organizações que trabalham } \\
\text { com o meio ambiente e com o } \\
\text { desenvolvimento rural sustentável. }\end{array}$ & $\begin{array}{l}\text { a) Qualidade nas condições } \\
\text { de trabalho; } \\
\text { belhoria na qualidade de } \\
\text { vida. }\end{array}$ & $\begin{array}{l}\text { a) Ser reconhecido e legitimado } \\
\text { no exercício do seu trabalho; } \\
\text { b) Ter condições de competir } \\
\text { dentro do mercado. }\end{array}$ \\
\hline
\end{tabular}




\begin{tabular}{|l|l|l|l|}
\hline Formas & a) Comissões de planejamento e & a) Auxílio de Órgãos, & a) Comitê que representa o \\
de realizar & execução das políticas públicas; & Empresas Públicas ou & grupo nas negociações; \\
tarefas & b) Parcerias e subcontratações quando & Privadas envolvidas na & b) União entre os lojistas de \\
& necessárias. & $\begin{array}{l}\text { solução dos resíduos; } \\
\text { b) Manutenção da associação } \\
\text { por meio de parcerias, } \\
\text { comércio dos materiais. }\end{array}$ & nas negociações. \\
& & &
\end{tabular}

Fonte: Desenvolvido pelos autores, 2017.

O problema a ser respondido na pesquisa é sobre a presença de tipos de comprometimento em redes de distintas naturezas. Para a coleta na forma de entrevista os sujeitos foram selecionados conforme seu tempo de participação na rede, sua liderança, sua posição e cargo na rede, ou sua participação na formação e desenvolvimento do grupo. Para a coleta de dados de fontes secundários foram selecionados documentos com acesso público, como atas de reuniões registradas em cartórios, notícias nos jornais locais do governo, notícias na mídia local e relatos técnicos de agentes que participam, ou participaram da formação e manutenção das redes.

O número de entrevistas seguiu o critério de saturação (SANDELOWSKY, 1995), encerrando-se a coleta quando os dados convergem de maneira evidente, sem novas informações.

Para a análise dos dados de entrevistas e de fontes secundárias que se apresentam na forma de discurso foi utilizado o conjunto de técnicas denominado análise de conteńdo (BARDIN, 2011), que consiste em inferir a ideia central de partes do discurso. A escolha dessa técnica se justifica quando existem variáveis pré-selecionadas e busca-se sua presença no discurso.

Os dados de fontes secundárias que se apresentam na forma de tabelas e gráficos foram analisados por técnicas de agrupamento. Essas análises não paramétricas permitem agrupamentos e análises de porcentagens e, conforme a amostra, algumas análises de correlações (SIEGEL, 1975).

\section{Apresentação e análise dos dados}

Foram investigadas três redes, sendo uma de economia solidária de Várzea Grande, no Mato Grosso, tendo a Asscavag como o ator central; uma de negócios de varejo, tendo o Shopping Popular de Cuiabá como ator central e uma de políticas ambientais de Várzea Grande, tendo a secretaria de meio ambiente como ator central.

\section{Rede de negócios do Shopping Popular}

O Shopping Popular de Cuiabá/MT é um grupo de vendedores ambulantes que se uniram a partir da iniciativa da prefeitura e pressões dos lojistas locais. A prefeitura cedeu um local e os vendedores assumiram o compromisso de cuidarem da infraestrutura e melhorias do entorno. Para essas ações o Shopping elegeu uma associação, que foi fundamental no reconhecimento da atividade jurídica legal do Shopping, tornando-o referência no comércio de produtos de varejo em Cuiabá.

Uma das mais importantes vitórias dos camelôs foi a participação na criação da Cooperativa de Compras do Comércio Popular de Mato Grosso - CooComp/MT responsável por viabilizar as compras internacionais, de forma legal. Conforme relato do atual presidente da associação do Shopping Popular: "Foi a partir dessa conquista que os camelôs deixaram de ser considerados contrabandistas".

Os problemas enfrentados por essa rede se referem exatamente a esse ponto, isto é, falta de leis, regulamentos e normas que legitimem as atividades dos cooperados e acabem com as reclamações e pressões dos lojistas. Assim, durante alguns anos, a rede tinha como principal objetivo a busca pelo reconhecimento e legitimidade no exercício de seu trabalho e, depois, veio o objetivo atual de competição no varejo popular. 
Foram realizadas três entrevistas, chegando-se ao ponto de exaustão. A análise resumida e os exemplos de discursos são apresentados no Quadro 5.

Quadro 5 . Resumo das análises de conteúdo dos atores da Rede do Shopping Popular de Cuiabá.

\begin{tabular}{|c|c|c|}
\hline Sujeito & Temática e partes dos discursos & Resposta da pesquisa \\
\hline $\begin{array}{l}\text { Sujeito 1- da } \\
\text { administração } \\
\text { do Shopping }\end{array}$ & $\begin{array}{l}\text { O discurso do sujeito é de uma rede unida, que tem } \\
\text { comprometimento social e comercial. Uma fala do } \\
\text { sujeito que ilustra é: "existe um ambiente de parceria, pois não } \\
\text { existe uma divida de um com outro, mas sim uma parceria". O } \\
\text { comprometimento mais presente é o econômico, seguido } \\
\text { pelo social e o institucional. }\end{array}$ & $\begin{array}{l}\text { Considerando o objetivo comercial } \\
\text { e o modo de funcionamento da } \\
\text { rede, sustenta-se a proposta de } \\
\text { dominância de comprometimento } \\
\text { econômico. }\end{array}$ \\
\hline Sujeito 2- lojista & $\begin{array}{l}\text { O discurso do sujeito aponta a presença de } \\
\text { comprometimento para não perderem as vantagens obtidas. } \\
\text { Uma fala que ilustra a análise: "as pessoas e organizaçoes } \\
\text { envolvidas com o Shopping Popular são comprometidas e a maioria } \\
\text { tem consciência de que as decisões que são tomadas não são para o } \\
\text { bem de um, mas para o bem de todos"; "que se todos ajudarem, todos } \\
\text { serão beneficiados". O comprometimento mais presente é o } \\
\text { econômico, seguido do racional. }\end{array}$ & $\begin{array}{l}\text { Convergente com os dados do } \\
\text { sujeito } 1 \text {, sustenta-se a proposição } \\
\text { de comprometimento econômico e } \\
\text { racional para uma rede com objetivo } \\
\text { comercial. }\end{array}$ \\
\hline Sujeito 3- lojista & $\begin{array}{l}\text { O discurso valoriza o ganho econômico por estar em } \\
\text { rede. Uma fala que ilustra esse ponto: "é mais vantajoso } \\
\text { estar em grupo, pois no grupo já existe uma clientela pronta que dá } \\
\text { segurança aos negócios e que se for sair do grupo vai ter gasto para } \\
\text { conquistar essa clientela". Secundariamente o sujeito valoriza o } \\
\text { comprometimento social, conforme ilustrado no discurso: } \\
\text { "nunca pensei em sair do grupo, que o Shopping popular é uma familia, } \\
\text { que tem muitas pessoas que começaram sua vida lá e que enfrentaram } \\
\text { muitos problemas e que por isso, aqueles que chegam, procuramos } \\
\text { mostrar o que já passamos, para dar valor". }\end{array}$ & $\begin{array}{l}\text { Os dados convergiram na } \\
\text { dominância do comprometimento } \\
\text { econômico, seguido do social. }\end{array}$ \\
\hline
\end{tabular}

Fonte: Desenvolvido pelos autores, 2017.

As entrevistas são convergentes em indicar a dominância do comprometimento econômico, com variações no segundo lugar, ora sendo o racional, ora o social. A análise confirma a valorização do comprometimento econômico, conforme indicado na Figura 1.

Como resposta ao problema de pesquisa destaca-se em primeiro lugar a natureza eminentemente comercial da rede, com tarefas e objetivos que são de atração de consumidores para o local de venda e sua satisfação, oferecendo qualidade, estrutura, segurança e variedade de produtos.

Existe, no entanto, um segundo objetivo, de natureza social, uma vez que o ator central, Shopping Popular, se esforçou no passado para o reconhecimento dos vendedores como pessoas honestas e negocia com os poderes públicos a realização de ações para a comunidade, com reciprocidade para o próprio Shopping.

Os dados permitem afirmar a sustentação da relação da natureza da rede (predominantemente comercial) com o comprometimento econômico. O comprometimento social, não privilegiado no desenho da proposição, pode ser explicado pela história de esforço dos lojistas do Shopping em obter legalidade e reconhecimento de sua atividade. Em terceiro lugar, sustentando a proposição, aparece o comprometimento racional.

Os dados são convergentes com afirmativas de autores (WILLIAMSON, 1981; PROVAN, KENIS, 2008; VERSCHOORE, BALESTRIN, 2008) sobre a dominância de aspectos racionais e econômicos em uma rede 
que tem sua natureza comercial explícita. Esses mesmos autores, no entanto, não descartam a presença e até a necessidade de ajustes nos processos da rede, o que só é possível pelo desenvolvimento de relações sociais de confiança e comprometimento.

\section{Rede de economia solidária dos catadores de recicláveis}

A rede de economia solidária analisada é um grupo com finalidade principal de inclusão social e participação no programa local de resíduos sólidos e consciência ambiental, as quais são alcançadas pela atividade econômica de coleta e venda de material reciclável. A rede interorganizacional apresenta organizações tais como Prefeitura Municipal de Várzea Grande, compradores de material, fornecedores de material (pessoas, condomínios, empresas), Arca Multincubadora, Universidade Federal de Mato Grosso, Instituto Alfa, BNDES, Grupo Amaggi (comprador e apoiador).

A cooperativa foco da rede, a Associação dos Catadores de Materiais Recicláveis de Várzea Grande - Asscavag, surgiu da união entre famílias de catadores de lixo de Várzea Grande. De acordo com relatos de catadores em vídeos disponíveis ao público no sítio eletrônico do YouTube, essa união teve como principal objetivo a melhoria nas condições de trabalho e, consequentemente, a melhoria na qualidade de vida dos catadores.

Foram realizadas quatro entrevistas, cujas análises se apresentam no Quadro 6.

Quadro 6 . Resumo da análise de conteúdo dos discursos dos sujeitos da Rede de Material Reciclável de Várzea Grande- MT.

\begin{tabular}{|c|c|c|}
\hline Sujeito & Temática e partes dos discursos & Resposta da pesquisa \\
\hline $\begin{array}{l}\text { Sujeito 1- } \\
\text { cooperado }\end{array}$ & $\begin{array}{l}\text { O comprometimento dominante é o afetivo, seguido } \\
\text { do social e o institucional. Ex. de discurso: "eu tenho a } \\
\text { sensação de realização com a existência do grupo e com aquilo que ele } \\
\text { possibilita". }\end{array}$ & $\begin{array}{l}\text { Há correspondência entre o objetivo } \\
\text { predominantemente social da rede e } \\
\text { a dominância de comprometimento } \\
\text { social e afetivo. }\end{array}$ \\
\hline $\begin{array}{l}\text { Sujeito } \\
\text { 2-cooperado }\end{array}$ & $\begin{array}{l}\text { O comprometimento dominante é o afetivo, seguido do } \\
\text { institucional e social. O trecho seguinte ilustra a função } \\
\text { social da rede: "o principal objetivo da união entre os catadores foi } \\
\text { a de tirar os catadores das ruas e do lixão". }\end{array}$ & $\begin{array}{l}\text { Convergente com a entrevista } \\
\text { anterior, há evidências de } \\
\text { dominância de comprometimento } \\
\text { afetivo e social, consoante com } \\
\text { a proposição. Como terceira } \\
\text { evidência surge o comprometimento } \\
\text { institucional. }\end{array}$ \\
\hline $\begin{array}{l}\text { Sujeito 3- } \\
\text { organização } \\
\text { comercial de } \\
\text { apoio }\end{array}$ & $\begin{array}{l}\text { O comprometimento dominante na rede interna } \\
\text { da cooperativa é o afetivo e o social, mas na rede } \\
\text { interorganizacional surgem vários, entre o institucional, } \\
\text { racional, econômico e social. O seguinte trecho ilustra } \\
\text { essa composição de racionalidade, compromisso social e } \\
\text { institucional: "o Projeto Gama e o Instituto Alfa auxiliaram no } \\
\text { objetivo de colocar a associação dentro da mais completa regularidade } \\
\text { para o seu devido funcionamento, uma vez que isso influenciou e } \\
\text { influencia diretamente nas parcerias firmadas". }\end{array}$ & $\begin{array}{l}\text { Este sujeito esclarece a divisão de } \\
\text { rede interna e externa e como os } \\
\text { comprometimentos aparecem de } \\
\text { forma distinta em cada nível. Esta } \\
\text { evidência lança uma nova questão } \\
\text { na pesquisa, que é a divisão entre } \\
\text { análises inter e intraorganizacional, } \\
\text { não considerada no planejamento. }\end{array}$ \\
\hline $\begin{array}{l}\text { Sujeito 4- } \\
\text { comprador de } \\
\text { material }\end{array}$ & $\begin{array}{l}\text { O comprometimento dominante é o econômico, conforme } \\
\text { evidente numa das primeiras falas do sujeito: "na relação } \\
\text { entre a Beta e a Asscavag não tem compromisso nenhum, sendo que } \\
\text { a Beta é uma empresa privada que compra e vende o material (papel } \\
\text { e papelão é o forte da Beta) mantendo uma relação estritamente } \\
\text { comercial". }\end{array}$ & $\begin{array}{l}\text { Esta resposta divergente pode ser } \\
\text { explicada pela posição e interesse } \\
\text { específico do ator na rede. É um } \\
\text { comprador que tem o objetivo } \\
\text { comercial dominante. }\end{array}$ \\
\hline
\end{tabular}

Fonte: Desenvolvido pelos autores, 2017. 
Essa rede valoriza os objetivos sociais, embora esteja implicada em objetivos comerciais e de políticas públicas. A organização foco da rede, a Asscavag, tem como função básica oferecer qualidade de vida aos associados, retirando-os do lixão que existe no município. Esse objetivo de inclusão social está vinculado ao comprometimento social, especialmente da diretoria, com sua história de migração de uma forma de vida para outra. A associação enfrenta alguns problemas, tais como qualidade de condições de trabalho e necessita do apoio do Estado e de outras organizações para realizar suas tarefas, mas esse apoio, que viria se existisse um forte comprometimento institucional das outras organizações, raramente é obtido.

Conforme hipótese construída na Figura 1, a natureza social dessa rede implicaria em comprometimento afetivo em primeiro lugar e social em segundo lugar. Os dados confirmam a presença mais forte desses tipos de comprometimento, comparados com os outros, mas não foi possível classificar um primeiro e segundo lugar a partir das entrevistas e das fontes secundárias.

Por outro lado, surgiu uma divisão entre rede interna da cooperativa e a rede de organizações envolvidas, com comprometimentos diferentes. $\mathrm{Na}$ rede interna houve sustentação da proposição, com valorização do comprometimento social e secundariamente com o comprometimento afetivo, mas na rede interorganizacional não há comprometimento dominante, variando conforme o discurso e posição do ator respondente.

Conclui-se que em redes com natureza de economia solidária, com objetivo social dominante, as relações sociais se destacam, confirmando a teoria de imersão social de Granovetter (1985) e dentro dessas relações sociais observa-se a presença dominante do tipo de comprometimento social e afetivo, especialmente visível na análise da rede interna da associação.

Vale ressaltar o percurso distinto desta rede, comparada com a anterior. Ambas nasceram de problemas sociais e econômicos (os camelôs e os catadores de rua), ambas foram apoiadas pelo governo, mas, desde o início, os líderes representantes impuseram objetivos diferentes, um mais comercial e outro mais social, determinando a estrutura, os processos e a matriz de relacionamento nas redes.
Conforme os autores puderam observar diretamente no Shopping Cuiabá, as práticas atuais pouco se relacionam com os objetivos iniciais de solução social. As regras de inclusão e permanência são essencialmente comerciais e administrativas. Já na Asscavag, conforme se observou em duas visitas, o ambiente geográfico e as práticas de produção são mais próximas de uma situação de fraternidade, de inclusão sem restrição.

Embora não seja o foco deste trabalho, conforme Gulati e Gargiulo (1999) e Halinen e Törnroos (1998), análises historicistas podem esclarecer a estrutura, a dinâmica e a matriz relacional atual de redes.

\section{Rede de políticas públicas da Secretaria de Meio Ambiente e Desenvolvimento Rural Sustentável}

A rede analisada está no município de Várzea Grande, mas com frequência as ações demandam a participação de outros municípios, como é o caso de ações de tratamento de rios, ou de reservas ambientais.

O município possui extensa área rural e não apresenta estrutura pública suficiente para atender a população residente nessas áreas. Com isso, alguns problemas comuns, como a falta de geração de renda, trouxeram como consequência a saída dos moradores das comunidades rurais, gerando concentração na área urbana, tornando mais crítica a situação de qualidade de vida.

Soma-se a esse problema alguns sinais de ineficiência dos últimos gestores da cidade na obtenção de resultados voltados para o combate à degradação do meio ambiente e para o estimulo ao desenvolvimento rural sustentável. A secretaria do meio ambiente e desenvolvimento rural realiza parcerias com instituições e empresas locais e essa rede é o escopo da investigação.

Foram realizadas quatro entrevistas, cujas análises são mostradas no Quadro 7. 
Quadro 7. Resumo da análise de conteúdo dos discursos dos sujeitos da

Rede de Políticas Públicas de Meio Ambiente de Várzea Grande- MT.

\begin{tabular}{|c|c|c|}
\hline Sujeito & Temática e trechos dos discursos & Resposta da pesquisa \\
\hline Sujeito 1- secretário & $\begin{array}{l}\text { O discurso básico do sujeito é sobre a ação de educação } \\
\text { e conscientização da população sobre questões } \\
\text { ambientais, o que indica um comprometimento social } \\
\text { dos parceiros. O seguinte discurso ilustra a análise: } \\
\text { "Nas escolas são feitas atividades de educaşão ambiental, como } \\
\text { ensinar a fazer sabão com óleo de coz̨inha usado e palestras de } \\
\text { conscientização e também existem empresas privadas que ajudam a } \\
\text { secretaria a realizar algumas açôes". } \\
\text { O comprometimento dominante é o social, seguido do } \\
\text { institucional. }\end{array}$ & $\begin{array}{l}\text { Considerando o objetivo } \\
\text { predominantemente educativo e de } \\
\text { preservação perseguido pela rede, } \\
\text { os dados indicam sustentação da } \\
\text { proposição de comprometimento } \\
\text { social como dominante, aparecendo } \\
\text { também o comprometimento } \\
\text { institucional, que não estava no } \\
\text { desenho proposto. }\end{array}$ \\
\hline $\begin{array}{l}\text { Sujeito } \\
\text { 2-coordenador dos } \\
\text { fiscais }\end{array}$ & $\begin{array}{l}\text { O comprometimento dominante é o social, seguido } \\
\text { do institucional. Um exemplo de discurso social é: "o } \\
\text { principal problema é a falta de conscientização da população, pois } \\
\text { não havendo essa consciência, não existe a prevenção, não existe } \\
\text { o combate à depredação ao meio ambiente". Um exemplo de } \\
\text { comprometimento institucional: "ninguém consegue ter êxito } \\
\text { nesse negócio trabalhando sożinho, dando ênfase ao trabalho da } \\
\text { secretaria que é no auxilio do suporte técnico àqueles que precisam } \\
\text { e sempre procurando esses parceiros, pois a parceria é fundamental } \\
\text { nesse trabalho". }\end{array}$ & $\begin{array}{l}\text { O comprometimento social } \\
\text { é o mais evidente no discurso, } \\
\text { correspondendo com a tarefa } \\
\text { de educação e consciência da } \\
\text { população. }\end{array}$ \\
\hline $\begin{array}{l}\text { Sujeito 3- consultor } \\
\text { de apoio }\end{array}$ & $\begin{array}{l}\text { O comprometimento dominante é o social, secundado } \\
\text { pelo comprometimento institucional, conforme se } \\
\text { infere de exemplos de discursos como o seguinte: "existe } \\
\text { parceria com várias empresas, que algumas vem a sua procura } \\
\text { não apenas por questões de obrigação de legislação, mas também } \\
\text { pela consciência das questões sociais e ambientais, e que algumas } \\
\text { empresas levam aos seus colaboradores a importância dessa } \\
\text { conscientização". } \\
\text { Como consultor de apoio à instituições que auxiliam as } \\
\text { políticas públicas, o sujeito colocou o comprometimento } \\
\text { econômico em terceiro lugar. }\end{array}$ & $\begin{array}{l}\text { O comprometimento social e } \\
\text { o institucional são dominantes, } \\
\text { sustentando parte da proposição } \\
\text { colocada na Figura } 1 . \text { O } \\
\text { comprometimento utilitarista não } \\
\text { foi sustentado. } \\
\text { A posição de consultor, com } \\
\text { remuneração, pode explicar a } \\
\text { presença do comprometimento } \\
\text { econômico. }\end{array}$ \\
\hline $\begin{array}{l}\text { Sujeito 4- empresa } \\
\text { parceira }\end{array}$ & $\begin{array}{l}\text { O comprometimento dominante é o social, seguido do } \\
\text { institucional. O segmento de discurso seguinte ilustra a } \\
\text { valorização do social, do institucional e nega o objetivo } \\
\text { econômico: "o principal motivo é o fim que o trabalho busca, on } \\
\text { seja, a melhoria para a sociedade...(sobre algum ganho financeiro) } \\
\text {... não existe esse ganho financeiro; que o interesse é o bem para } \\
\text { a comunidade, que fazendo o bem à comunidade, também estão } \\
\text { fažendo o bem para a imagem da empresa". }\end{array}$ & $\begin{array}{l}\text { Convergente com os discursos } \\
\text { anteriores, o comprometimento } \\
\text { social e o institucional } \\
\text { aparecem como dominantes. O } \\
\text { comprometimento utilitarista não } \\
\text { apareceu. }\end{array}$ \\
\hline
\end{tabular}

Fonte: Desenvolvido pelos autores, 2017.

Considerando a análise dos discursos, as organizações da rede valorizam os objetivos de políticas públicas, principalmente o desenvolvimento rural sustentável, o que implica em tarefas de conscientização e participação da sociedade, tais como palestras e acordos com empresas. O maior problema da rede é exatamente obter o resultado dessa conscientização e o segundo problema é o limite de ação do Estado, por falta de recursos de toda ordem. 
Essa situação, conforme hipótese construída no desenho, implicaria em comprometimento social, institucional e utilitarista na terceira posição. A proposta se confirma no comprometimento social e institucional, este último indicando certa pressão para que os atores participem de ações coletivas. $\mathrm{O}$ comprometimento utilitarista não foi citado, mas as gravações das entrevistas indicam que as questões foram compreendidas, mostrando que não é um problema do instrumento.

Potipiroon e Ford (2017) investigando comprometimento em políticas públicas afirmam que o comprometimento afetivo depende da existência de um líder motivacional. Aceitando essa perspectiva, pode-se afirmar que falta um líder, seja pessoa, ou organização, que motive os atores e desenvolva a consciência ambiental.

\section{Resposta ao problema de pesquisa}

Unindo-se as respostas sobre os tipos de comprometimento dominante foi possível construir a Figura 2, que mostra na esquerda o resultado esperado e na direita o resultado obtido.

A primeira conclusão é que a afirmativa sobre tipos especiais de comprometimento em redes de distintas naturezas foi sustentada, já que cada tipo de comprometimento aparece predominantemente em um tipo de rede e secundariamente numa segunda rede, ou aparece uma vez só, como é o caso do comprometimento econômico.

A constatação dessa correspondência é um dado importante, que pode indicar regularidades num campo (de estudos de redes) onde se afirma a imprevisibilidades e variabilidade (GRANDORI, 1997; SCHNEIDER, 2005, MATURANA, VARELA, 1987). A ausência de correspondência, como ocorre com o comprometimento utilitarista, também tem sua importância. Nos três tipos de redes não existiram sinais de compromisso no sentido de aprender técnicas, conhecer processos, ou domínio de ferramentas para uso na empresa.

A segunda análise, agora considerando o ponto a ponto de cada comprometimento com cada rede, mostra uma parte de sustentação da proposição e uma parte de divergência. Lembrando que as correspondências foram construídas a partir das afirmativas dos autores, é possível discutir se elas se modificam conforme o contexto e história de cada rede. Por exemplo, a história singular da Asscavag, com os diretores saindo do lixão para fundar a associação, é um forte fator de dominância de comprometimento afetivo. Trabalhos dos autores (não publicados) com outras cooperativas, de São Paulo e Campinas, mostram o institucional como comprometimento forte e o afetivo em segundo plano.

Estudos historicistas de redes (HALINEN, TORNROOS, 1998) que selecionam um eixo ordenador, afirmam que o eixo social, especialmente a confiança, o comprometimento e o poder, explicam parte da organização estrutural e de funções na rede. É uma afirmativa um pouco além das pretensões do artigo, mas mostra a força da história da matriz de relacionamentos e dos objetivos na presença do tipo de comprometimento. Estudos historicistas desses três casos poderiam testar as afirmativas.

O comprometimento institucional apareceu para as três redes, sendo a dominante exatamente aquela proposta na Figura 1. Sua extensão para as outras duas pode ser um sinal que esse comprometimento é mais básico, mais presente, mais necessário para as redes, independentemente de sua natureza. É um resultado que indica a possibilidade e interesse em replicações da pesquisa. Se o comprometimento institucional aparecer de forma frequente em várias redes distintas, pode indicar uma variável independente da natureza da rede.

Figura 2 . Desenho da proposta da pesquisa (lado esquerdo) e do resultado da pesquisa (lado direito).

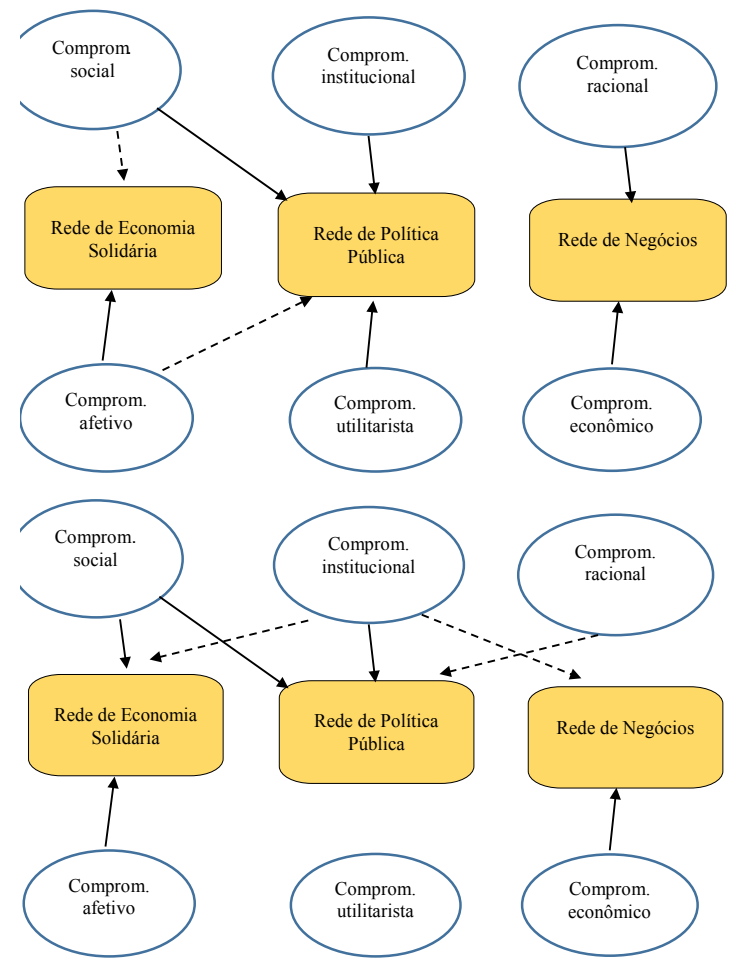

Fonte: Elaborado pelos autores, 2017. 
O comprometimento econômico apresentou o resultado esperado. Sua correspondência dominante é com a rede comercial. No entanto, ele foi citado na rede de economia solidária (por um sujeito que é comprador de material) e na rede de políticas públicas (por um sujeito que ajuda empresas a obterem ganhos financeiros nos programas do governo). Apesar dessas citações, o comprometimento econômico não tem a mesma força de presença do institucional.

O comprometimento utilitarista é o ausente nos resultados. Lembrando que o seu conceito significa usufruir do aprendizado de técnicas e de processos, pode-se inferir que nas três redes não há interesse sobre aprender práticas. Os autores que citam esse tipo de comprometimento dão exemplos de redes horizontais, com empresas homogêneas (GARNIER, 2009). Talvez essa diferença de estrutura explique a ausência do comprometimento utilitarista nas três redes. Trabalhos sobre redes de pequenos agricultores no Brasil (BERTOLI, 2015; VILANOVA, 2016) indicam que aprender com os outros é um dos motivadores de criar comprometimento no grupo.

$\mathrm{Na}$ rede de políticas públicas, a proposta era pela presença do comprometimento predominantemente social e ele foi confirmado pelos dados. O comprometimento institucional marcou presença nessa rede, com dedicação às tarefas e crença nos objetivos sociais das organizações envolvidas. Segundo Borzel (1998), no entanto, a implantação de políticas públicas é um campo que apresenta contradições nas práticas e nas explicações sobre elas, incluindo o comprometimento das organizações e da sociedade.

A rede de economia solidária sustentou as correspondências propostas na Figura 1. As características constantes em redes de economia solidária, como valorização do objetivo social, esforço de legitimação e ações de busca de benefícios levaram à seleção do comprometimento afetivo, o social e o institucional. A história de vida dos fundadores, dois dos quais foram entrevistados, é o ponto de ligação entre os atores, determinando o comprometimento afetivo.

Sobre a operacionalidade e validade dos instrumentos, o roteiro de entrevista mostrou-se capaz de gerar dados (o que indica operacionalidade) e mostrou capacidade de diferenciar tipos de comprometimento (o que indica confiabilidade). As fontes secundárias foram úteis em mostrar as relações institucionais entre os atores, como prefeitura, cooperativa, empresas com apoio social e Ongs.
Cabe informar que foi construído um questionário a partir dos indicadores, na forma de escala de Likert, com cinco pontos, mas os pesquisadores só obtiveram autorização para aplicar no Shopping Cuiabá, com pessoas indicadas pela administração do Shopping. Nessa condição, a coleta foi realizada, até para não comprometer futuras pesquisas no local, mas as 14 respostas obtidas não foram incluídas na análise.

\section{Conclusões}

Artigos mais recentes sobre a abordagem social de redes (MAK, RAPOPORT, 2013; POTIPIROON, FORD, 2017) repetem afirmativas de autores clássicos sobre a importância do comprometimento no desenvolvimento das redes. A discussão é válida porque na primeira década do grande desenvolvimento e legitimação do campo de redes, que foi em 1990, o conceito de comprometimento utilizado era oriundo da produção sobre organizações isoladas, especialmente as afirmativas de Morgan e Hunt (1994). Aos poucos se entendeu e se aceitou que o comprometimento em redes tem outra natureza, coletiva, e não se reduz apenas à relação de alguém com uma instituição.

O presente trabalho se coloca nesse movimento de renovação e valorização do tema do comprometimento e sua proposta é afirmar a correspondência entre os tipos de redes e as distintas manifestações de comprometimento, a partir de um quadro conceitual de seis definições. A questão se coloca no debate sobre a presença repetida e a generalidade de variáveis nas redes, contando com extensa produção que busca os eixos, as bases, os fundamentos das redes e, por outro lado, sobre a especificidade e unicidade de cada rede, conforme a linha que segue preceitos de incertezas, imprevisibilidades e construções sociais específicas de cada grupo.

Os resultados não foram conclusivos sobre as duas posições. A Figura 2 mostra a variância de comprometimento, sustentando a posição da especificidade e unicidade, mas o comprometimento institucional se espalhou pelas redes, indicando possível generalidade. O debate fica em aberto e uma das variações possíveis de pesquisa seria com redes de igual natureza. Será que redes da mesma natureza mostrariam o mesmo comprometimento?

Outro ponto levantado pela pesquisa refere-se ao contexto. Os três casos investigados, embora com 
proximidade geográfica, apresentam ambientes organizacionais bem distintos. A rede de economia solidária é gerenciada, em boa parte, pela empresa local, de grande porte, com seu programa de responsabilidade social, determinando alguns processos e formalidades. Sem esse apoio financeiro e social a cooperativa não existiria e não se manteria atualmente. A prefeitura é ator espectador nessa rede, participando com a infraestrutura do local e pouco age para combater o verdadeiro problema, que é o lixão local.

Já na rede de negócios, o Shopping Popular de Cuiabá adquiriu posição de ator central, com organização administrativa e com independência da prefeitura. Atualmente o Shopping é que ajuda a prefeitura, mantendo a qualidade ambiental do local e repassando impostos antes inexistentes. Pode-se afirmar que a história do Shopping passou de uma fase de solução social para um estado comercial estabelecido.

A rede de políticas públicas ambientais apresenta-se menos organizada que as redes anteriores, quando se considera a quantidade de participantes ativos, os resultados das ações e o comprometimento dos atores. Discursos dos atores do poder público, conforme mostrados nos resultados, são voltados para o que se pretende fazer e não para o que se fez. Outros trabalhos sobre implantação de políticas ambientais no brasil apontam o gargalo no momento da participação de todos nas ações coletivas (GIGLIO, LUIZ, NAJBERG, 2013)

Embora não sendo a proposta deste artigo, ele abriu o tema do contexto e sua relação com as formas de comprometimento dos atores.

Assim, um primeiro benefício teórico do trabalho foi construir uma ponte entre características da rede e a categoria comprometimento. A revisão bibliográfica e a base teórica mostraram uma lacuna sobre essa interface, embora os autores se refiram a elas como importantes (MORGAN, HUNT, 1994; GULATI, GARGIULO, 1999; ANDERSON, WEITZ, 1992). Ao final, a pesquisa provê evidências da correspondência, sustentando a proposição de especificidades de tipos de redes e tipos de comprometimento.

Ainda no plano teórico, um dos valores do artigo consiste em discutir a questão da generalidade versus especificidade de presença de variáveis nas redes, conforme seu tipo e estrutura. Os dados sustentam mais fortemente a posição da especificidade, a qual foi colocada como proposição orientadora do artigo.
Outro benefício teórico do trabalho, não planejado, mas presente na pesquisa, é abrir o tema da importância do contexto, do ambiente, sobre a presença de formas específicas de governança.

Um primeiro benefício metodológico consiste na organização de variáveis que distinguem uma rede. Existem muitos conceitos sobre o que determina e qualifica um formato de rede, conforme lentes teóricas diversas. Neste artigo agrupamos algumas dessas variáveis num conjunto que é facilmente investigado, operacional e pode ser um quadro útil para pesquisas.

Um benefício metodológico importante do artigo é a apresentação de um conjunto de indicadores de caracterização das redes e um conjunto de indicadores de seis definições de comprometimento. Os indicadores qualitativos sobre redes são raros na produção acadêmica brasileira e sua ausência implicou na difícil tarefa de construir os indicadores um a um, a partir de material disperso. Além disso, as divisões clássicas de comprometimento chegam a 4 definições, no máximo, e nós criamos um quadro com seis definições e seus indicadores.

Os indicadores mostraram-se operacionais, isto é, as questões são entendidas pelos respondentes e o mesmo roteiro pode ser aplicado em distintos sujeitos, com educação, cargos e experiências diversas. Os indicadores mostraram-se confiáveis, isto é, o conteúdo das respostas é coerente com o objetivo de coleta de cada um deles. Essas duas condições favoráveis- operacionalidade e confiabilidadepermitem o uso dos indicadores para novas pesquisas.

A dúvida sobre os indicadores reside no comprometimento utilitarista, que não apareceu em nenhum discurso, existindo quatro linhas de explicação: (a) o conceito não está apropriadamente definido; (b) os indicadores não são claros e eficazes para indicar a presença desse tipo de comprometimento; (c) esse tipo de comprometimento está incluso em outra categoria e não se pode distingui-lo; (d) de fato não há esse comprometimento nas três redes. As gravações das entrevistas e a observação na aplicação dos questionários não indicam que os itens (a) e (b) sejam as explicações. A explicação (c) pode ser discutida, já que o utilitarismo pode estar dentro do racional.

Finalizando, o artigo, de caráter exploratório, abre campos de discussão sobre o que caracteriza uma rede, sobre dominância (ou não) de tipos de comprometimentos em distintas redes e sobre a 
construção e validade de indicadores específicos para o fenômeno de ação coletiva nas redes, cuja produção ainda é emergente na academia brasileira.

\section{Referências}

ANDERSON, E.; WEITZ, B. The use of pledges to build and sustain commitment in distribution channels. Journal of Marketing Research, v.29, n.1, p.18-34, 1992.

ANJOS, F.; REAGANS, R. Commitment, Learning, and Alliance Performance: A Formal Analysis Using an Agent-Based Network Formation Model. The Journal of Mathematical Sociology, v.37, n.1, p.123, 2013.

ANTUNES, J.; BALESTRIN, A.; VERSCHOORE, J. Práticas de gestão de redes de cooperação. São Leopoldo, RS: UNISINOS, 2010.

BALESTRIN, A.; VERSCHOORE, J.; REYES, E. The field of studies of interorganizational cooperation networks in Brazil. Revista de

Administração Contemporânea, v.14, n.3, p.458477, 2010.

BARDIN, L. Análise de conteúdo. São Paulo: Edição 70, 2011.

BASTOS, A. et al. Vínculos dos indivíduos com a organização: análise da produção científica brasileira 2000-2010. Psicologia: Teoria e Pesquisa. Brasilia: UnB. Impresso, 2014.

BERTOLI, N. A confiança e o comprometimento como eixos organizadores dos estados de redes: proposta conceitual e estudo de casos do agronegócio do norte do Paraná. Dissertação (Mestrado). Universidade Paulista - UNIP Programa de Pós-Graduação em Administração, São Paulo, 2015.

BÖRZEL, T. Organizing Babylon $\square$ On the Different Conceptions of Policy Networks. Public Administration, v.76, n.2, p.253-273, 1998.

BOZIONELOS, N. Intra-organizational network resources: how they relate to career success and organizational commitment. Personnel Review, v.37, n.3, p.249-263, 2008.

BRAGA, M.; GOMES, L.; RUEDIGER, M. Mundos pequenos, produção acadêmica e grafos de colaboração: um estudo de caso dos Enanpads. Revista de Administração Pública, v.42, n.1, p.133-154, 2008.

CLARKE, N. The relationships between network commitment, its antecedents and network performance. Management Decision, v.44, n.9, p.1183-1205, 2006.

DIMAGGIO, P.; POWELL, W. The iron cage revisited: institutional isomorphism and collective rationality in organizational fields. American Sociological Review, v.48, p.147-160, 1983.

FRANÇA, G. A problemática da economia solidária: um novo modo de gestão pública? Cadernos EBAPE.BR, v.2, n.1, p.2-18, 2004.

GAMBA, J. Os Estados De Organização De Redes De Negócios: Discussão E Exemplos Das Redes Nas Quais Estão Presentes As Cooperativas Habitacionais De São Paulo. Dissertação (Mestrado). Universidade Paulista - UNIP Programa de Pós-Graduação em Administração, São Paulo, 2014.

GARNIER, M. Search engine loyalty: considering the commitment-loyalty link from a hedonic versus utilitarian perspective. International Journal of Internet Marketing and Advertising; v.5, n.1/2, p.43-58, 2009.

GENARI, D.; FACCIN, K.; MACKE, J. Measuring organizational commitment in Brazilian wine industry networks. REAd. Revista Eletrônica de Administração, Porto Alegre, v.19, n.2, p.351-383, ago. 2013.

GIGLIO, E.; RYNGELBLUM, A. Uma investigação sobre o ator consumidor na rede de pirataria e uma proposta de alternativa de estratégia de combate. Revista de Administração Mackenzie - RAM, São Paulo, v.10, n.4, p.131-155, jul./ago., 2009.

GIGLIO, E.; LUIZ, A.; NAJBERG, E. As relações sociais como fatores determinantes na rede de implementação de políticas ambientais rurais: investigação a partir de alguns municípios do Estado de São Paulo. Revista Desenvolvimento em Questão, v.11, n.24, p.169-203, 2013.

GRANDORI, A. An organizational assessment of inter-firm coordination modes. Organization Studies, v.18, n.6, p.897-925, 1997. 
GRANOVETTER, M. Economic Action and Social Structure: A Theory of Embeddedness. American Journal of Sociology, v.91, n.3: p.481-510, 1985.

GULATI, R.; GARGIULO, M. Where do interorganizational networks come from? American Journal of Sociology, v.104, n.5, p.1439-1493, mar., 1999.

HALINEN, A.; TÖRNROOS, J. The role of embeddedness in the evolution of business networks. Scandinavian Journal of Management, v.14, n.3, p.187-205, 1998.

HIGA, W. As redes de economia solidária: divergência entre cidadania e inovação tecnológica. In: I Simpósio Estadual Lutas Sociais América Latina, Londrina/Pr., 2005.

HOFFMAN, V.; MOLINA-MORALES, X.; MARTÍNEZ-FERNÁNDEZ, M. Redes de empresas: proposta de uma tipologia para classificação aplicada na indústria de cerâmica de revestimento(1). Revista de Administração Contemporânea, v.11, n.esp., p.103-127, 2007.

KIM, Y.; RHEE, M. The Contingent Effect of Social Networks on Organizational Commitment:

A Comparison of Instrumental and Expressive Ties in A Multinational High-Technology Company. Sociological Perspectives, v.53, n.4, p.479-502, 2010.

LEE, J.; KIM, S. Exploring the Role of Social Networks in Affective Organizational Commitment: Network Centrality, Strength of Ties, and Structural Holes. American Review of Public Administration, v.41, n.2, p.205-223, 2011.

MAK, V.; RAPOPORT, A. The price of anarchy in social dilemmas: Traditional research paradigms and new network applications. Organizational Behavior and Human Decision Processes, v.120, n.2, p.142153, 2013.

MATURANA, H., VARELA, F. The Tree of Knowledge: The Biological Roots of Human Understanding. Boston: Shambhala, 1987.

MEYER, J.; ALLEN, N. A three-component conceptualization of organizational commitment.

Human Resources Management Review, v.1, n.1, p.61-89, 1991.

MILES, R.; SNOW, C. Organization theory and supply chain management: An evolving research perspective. Journal of Operations Management, v. 25, n.2, p.459-463, 2007.

MORGAN, R.; HUNT, S. The commitment-trust theory of relationship marketing. Journal of Marketing, v.58, p.20-38, jul., 1994.

MOWDAY, R., PORTER, L.; STEERS, R.

Employee-organization linkages - the psychology of commitment, absenteeism and turnover. New York: Academic Press, 1982.

OLIVER, A.; EBERS, M. Networking network studies: an analysis of conceptual configurations in the study of inter-organizational relationships. Organization Studies, v.19, n.4, p.549-583, 1998.

PÉREZ, N.; HIDALGO, V.; INCLAN, C. Socio-cognitive paradigm in the Social Network Dreamcatchers in Cuba. Información, Cultura y Sociedad; v.36, p.11-27, 2017.

PFEFFER, J.; SALANCIK, G. The external control of organizations: a resource dependence perspective. New York: Harper \& Row, 1978.

POTIPIROON, W.; FORD, M. Does Public Service Motivation Always Lead to Organizational Commitment? Examining the Moderating Roles of Intrinsic Motivation and Ethical Leadership. Public Personnel Management, v.46, n.3, p.211-238, 2017.

PROVAN, K.; KENIS, P. Modes of network governance: Structure, management, and effectiveness. Journal of Public Administration Research and Theory, v.18, n.2, p.229-252, 2008.

REGO, A. et al. Espiritualidade nas organizações e comprometimento organizacional. RAE - Revista de Administração de Empresas, v.6, n.2, jul.-dez., 2007.

ROBERTS, K.; O'REILLY, C. Some Correlates of Communication Roles in Organizations. Academy of Management Journal, v.22, p.42-57, 1979.

SAFARI, A.; ABDEALI, G. Analysis of the role of organizational commitment and social network ties on organizational citizenship behavior case study: University of Isfahan Staff. International Journal of Management, IT and Engineering, v.3, n.10, p.43-57, out., 2013.

SALANCIK, G. Commitment and the control of organizational behavior and belief. In:STAW, 
B., SALANCIK, G. (eds.). New directions in organizational behavior. Chicago: St. Clair, 1977.

SANDELOWSKY, M. Sample size in qualitative research. Research in Nursing and Health, v.18, n.2, p.179-83, 1995.

SCHNEIDER, V. Redes de políticas públicas e a condução de sociedades complexas. Civitas, v.5, n.1, p.29-58, 2005.

SIEGEL, S. Estatística não-paramétrica para as Ciências do Comportamento. São Paulo: McGrawHill, 1975.

TICHY, N.; TUSHMAN M.; FOMBRUM C. social Network Analysis for Organizations. Academy of Management Journal, v.4, n.4, p.507-519, 1979.

VERSCHOORE, J.; BALESTRIN, A. Fatores relevantes para o estabelecimento de redes de cooperação entre empresas do Rio Grande do Sul.

Revista de Administração Contemporânea- RAC, v.12, n.4, p.1043-1069, 2008.

VILANOVA, M. A confiança e o comprometimento como bases para o desenvolvimento de redes. Dissertação (Mestrado). Universidade Paulista - UNIP Programa de PósGraduação em Administração, São Paulo, 2016.

XIAO, Y. et al. Trust, relationship commitment and cooperative performance: supply chain management. Chinese Management Studies, v.4, n.3, p.231-242, 2010.

WILLIAMSON, O. The economics of organization: the transaction cost approach. The American Journal of Sociology, v.87, n.3, p.548-577, 1981. 